\title{
Barriers and facilitators of providing primary health care to Afghan refugees: A qualitative study from the perspective of health care providers
}

\author{
Nemat Azizi ${ }^{1}$, Bahram Delgoshaei*2 (D), Aidin Aryankhesal ${ }^{2}$ \\ Received: 21 Feb 2019 \\ Published: 4 Jan 2021
}

\section{Abstract}

Background: One of the important aspects in the field of refugee health is the availability of primary health care, and the quality improvement of health care requires identifying barriers and facilitators. The present study aimed to identify obstacles and facilitators of providing primary health care to Afghan refugees from the perspective of health care providers.

Methods: In this qualitative study, a semi-structured interview was conducted based on purposeful sampling with the involvement of 21 managers and experts in primary health care centers. Data were analyzed using the content analysis method and MaxQDA.

Results: Data analysis led to the production of 4 main themes: (1) challenges while providing primary health care, with 10 subthemes; (2) challenges after providing care, with 4 subthemes; (3) opportunities, with 3 subthemes; and (4) solutions, with 6 subthemes.

Conclusion: According to the results of this study, identifying the challenges and providing opportunities and solutions to existing problems seem to be effective steps in the quality improvement of providing primary health care to refugees.

Keywords: Barriers, Facilitator, Primary health care, Health care providers, Refugees

Conflicts of Interest: None declared

Funding: None

\section{*This work has been published under CC BY-NC-SA 1.0 license.}

Copyright $($ Iran University of Medical Sciences

Cite this article as: Azizi N, Delgoshaei B, Aryankhesal A. Barriers and facilitators of providing primary health care to Afghan refugees: A qualitative study from the perspective of health care providers. Med J Islam Repub Iran. 2021 (4 Jan);35:1. https://doi.org/10.47176/mjiri.35.1

\section{Introduction}

The Afghan migration to the countries of the region, especially Iran, is one of the forms of international migrations that has increased in recent decades (1). Afghans constitute the largest refugee group worldwide (2). The largest Afghan refugees reside in Iran. The 2015 report of UN High Commissioner for Refugees (UNHCR), which was released in December 2014, shows that 982027 registered refugees live in Iran, and according to the same report, the Islamic Republic of Iran hosts the largest urban refugee population in the world $(2,3)$. Refugees often have multiple and complex health care needs due to inequalities in health

Corresponding author: Dr Bahram Delgoshaei, delgoshaei.b@iums.ac.ir

1. Social Determinants of Health Research Center, Saveh University of Medical Sciences, Saveh, Iran

2. Department of Health Sciences Management, School of Health Management and Information Sciences, Iran University of Medical Sciences, Tehran, Iran determinants, prosecution, torture, or other forms of harm, deprivation and unhealthy environmental conditions, and the lack of access to health care (4). Ensuring primary health care for refugees is a global concern (4). The primary health care provides access to the health care system for all new needs and problems (2). The speed and mobility of people at the international level are the results of a change in the global pattern of diseases that may have challenges for immigrants who carry these diseases and a challenge for health care professionals who may not be familiar with these diseases (5). In other words, there is a higher risk of

\section{$\uparrow$ What is "already known” in this topic:}

Refugees often have multiple and complex health care needs, but they do not have access to health care. Primary health care services should fulfill the health care needs of refugees. Ensuring primary health care for refugees is a global concern.

\section{$\rightarrow$ What this article adds:}

Identifying the challenges and providing opportunities and solutions to existing problems seem to be effective steps in improving the quality of primary health care services to refugees. 
such illnesses in refugees due to poor health habits and a reduction in life expectancy (6). Yazdanpanah et al studied patients who referred to Masih Daneshvar hospital and found that Afghan patients were younger than Iranian patients and that these patients were more likely to develop sputum smear (3). Although refugees come from many countries and cultures, their common experiences cause them to be expanded to health care challenges and needs (6). In the study of Spike et al, it was found that small number of physicians and high health care costs were among the challenges faced by refugees (7).

In Iran, the Ministry of Health, Treatment, and Medical Education is responsible for the primary health care program for refugees, in addition to the Iranian population, and the Ministry deputyship is directly in charge of implementing the primary health care programs. Primary health care is provided free of charge in urban and rural health centers and in urban health clinics for refugees and immigrants. These services include the vaccination of neonates at birth, vaccination of children and pregnant women, providing care to pregnant women, child care, screening, and health training, which are done free of charge for authorized (with valid residence cards) and unauthorized (without a residence card) refugees and migrants.

Refugees constitute a large population in Iran (3), and this vulnerable group needs more access to primary care (8). In various studies, the direct/indirect effect of refugees' health on the health of the host country is significant and evident in areas such as the transmission of contagious diseases $(3,9)$. The psychophysical well-being of refugees is crucial for the effective resolution of the challenges and problems of living in the new country, and it is essential for full involvement in cultural, social, and economic life (4). Qualitative studies provide a basis for other studies. Thus, considering the lack of quantitative and qualititive information in Iran about primary health care of Afghan refugees, this study was conducted with a qualitative approach. Since there is no scientific model for primary health care in this population, the present study aimed to investigate the barriers and facilitators of providing primary health care to Afghan refugees from the perspective of health care providers.

\section{Methods}

\section{Study type and setting}

This was a qualitative study with content analysis approach. Content analysis in qualitative research is a favorable method to provide clear and concise evidence about the subject matter (10). Content analysis was used as a research method for the subjective interpretation of the content of interview data through a systematic classification process of coding and identifying concepts or patterns. All primary health care providers, experts, managers, and experienced individuals in the field of providing primary health care to refugees in urban and rural health centers, comprehensive health centers, health clinics, health deputyship of the Ministry of Health and Saveh University of Medical Sciences, Iran, were studied in 2015-2018. Iran is located in Southwest Asia (11), where the largest Afghan immigrants reside (3). The city of Saveh in Markazi province, is one of the 2 authorized cities for Afghan refugees for travel and living. The city of Saveh has 17 urban and rural health centers, 7 health clinics, and 52 health houses. Health centers are responsible for community health care and are the first place to provide health care services to people and refugees (12).

\section{Participants}

In the present study, the managers and experts were selected by purposeful sampling which continued until data saturation and repeated cases. The purpose of this sampling method is to obtain rich information in line with the objectives of the study $(13,14)$. The information in this study was saturated by performing 19 semi-structured interviews; in addition, 2 other interviews were conducted with the participants to ensure information saturation. After interviewing 19 health care providers, no new subtheme was found, so data saturation was achieved.

\section{Data collection and analysis}

Data were collected using semi-structured interviews with probing questions in a private place. The interview guide form was prepared with the assistance and guidance of a doctoral advisor and thesis supervisor. In the interview guide, all questions were open-ended, and the interview began with the following question: Please define your experiences in providing primary health care to refugees? Then, the interview was directed considering the goals of the research. Voice recorder and note-taking were also used at this stage.

The researcher began his research after obtaining permission from the following organizations: Saveh University of Medical Sciences; the protection and management of health centers; and the health house. Also, informed consent was obtained from health care providers. Semi-structured faceto-face interviews were used for data collection. Health care providers, including nurses, midwives, health experts, and technicians, with work experience in providing primary health care services to refugees who were interested in participating in the study were interviewed. The researcher conducted interviews and he officially invited people to the interview. Interviews were conducted at the place selected by the interviewees. The duration of interviews varied between 35 to 57 minutes. Open-ended questions allowed participants to fully explain their experiences with primary health care. The researcher tried to relate to and state the experiences of refugees and administrators in receiving primary health care. Interviews began with the following questions: What causes refugees to refer to health care centers more? What causes the refugees not to refer to such centers? What factors affect the service delivery to refugees? The interviews were conducted until data saturation was achieved. After the interview, data were analyzed. Interviewing and data collection were done simultaneously. With the permission of the participants, all interviews were recorded and notes were also taken to ensure that all important information have been included. In the case of ambiguity in the participants' statement, ambiguous points 
were clarified and resolved. For data analysis, the framework analysis method was used in 7 steps: (1) transcription, (2) familiarization with the interview, (3) coding, (4) developing a working analytical framework, (5) applying the analytical framework, (6) charting data into the framework matrix, and (7) interpreting the data (15). The researcher identified key concepts and subjects and provided a thematic framework. Then, he reviewed all the notes taken during the interviews based on the thematic framework and compared the concepts, experiences, contradictions, and suggestions. MAXQDA 10 was also used.

\section{Ethical considerations}

The ethical committee of Iran University of Medical Sciences approved this study (No. IUMS/SHMIS-1394/37). The optional presence and withdrawal of participants and the objectives of the study were verbally explained to the participants. They also ensured that their information would be kept confidential and only be used for research.

\section{Results}

Participants in this study were 12 men and 9 women, with a mean age of 44 years. Also, the majority of participants were undergraduates. On average, the participants had 18 years of work experience and management background (Table 1).

Content analysis included 4 main themes of the challenges: (1) while providing primary health care, (2) after providing primary health care, (3) opportunities, and (4) solutions. Subthemes of challenges while providing health care services included lack of trained and professional personnel, identification and identity records, communication, insurance, past medical and health records, training, interorganizational information exchange, refugee identity, number of children, family members, and vaccination. The subthemes of challenges after providing health services were as follow: access to refugees after receiving primary health care, leaving and discontinuing treatment, referral, and lack of proper information structure. Opportunity subthemes included the provision of free primary health care, refugees' access to health care services, justice, and equity. The subtheme of solutions included insurance, training, understanding refugee's language, identifying needs, comprehensive information system, and codifying service delivery instructions.

\section{A. Challenges while providing primary health care \\ A.1) Absence and lack of trained and professional per- sonnel}

Personnel currently engaged in providing refugees' health care services have not passed a specialized refugee health care course. This is one of the challenges that has been raised frequently by health care providers. Also, the provision of health care services by indigenous people and Iranians is another challenge.

"We have not passed any course related to refugees and how to provide health care services to them. So, we have worked in these years based on our experience and learned how to deal with them, and because we provide services both to Iranians and refugees, we have a heavy workload, and there are no new staff at this time." (Participant No. 3).

\section{A.2) Records of identification}

The lack of information to identify refugees was the most fundamental challenge and problem. Refugees do not provide any evidence of identity when they visit a center or office in Iran for the first time, declaring that they do not have such documents.

"When the Afghans refer to us, and we ask them to give an identity card, they have no birth certificates, no national cards, nor even passports, and thus they have illegally crossed the border. When we do not have any information, we have to accept what they say about themselves. We also ask their age, but they do not know how old they are." (Participant No. 6).

Table 1. Demographic characteristics of health care providers

\begin{tabular}{|c|c|c|c|c|c|c|}
\hline Participant Code & Gender & Age & Marital status & Education & Position & Work experience \\
\hline 1 & Female & 52 & Married & Diploma (social worker) & Health care provider & 24 \\
\hline 2 & Male & 42 & Married & B.S & Health care provider and manager & 15 \\
\hline 3 & Female & 55 & Married & Diploma (social worker) & Health care provider & 29 \\
\hline 4 & Female & 32 & Married & Associate degree & Health care provider and manager & 10 \\
\hline 5 & Male & 34 & Married & B.S & Health care provider and manager & 10 \\
\hline 6 & Male & 51 & Married & Diploma & Health care provider & 28 \\
\hline 7 & Male & 26 & Married & B.S & Health care provider & 2 \\
\hline 8 & Female & 52 & Divorced & B.S & Health care provider & 28 \\
\hline 9 & Male & 56 & Married & Diploma & Health care provider & 29 \\
\hline 10 & Male & 39 & Married & Associate degree & Health care provider and manager & 14 \\
\hline 11 & Female & 40 & Married & B.S & Health care provider and manager & 12 \\
\hline 12 & Female & 43 & Single & B.S & Manager & 18 \\
\hline 13 & Male & 45 & Married & Diploma & Health care provider & 23 \\
\hline 14 & Male & 38 & Married & B.S & Manager & 12 \\
\hline 15 & Male & 46 & Married & $\mathrm{PhD}$ & Manager & 19 \\
\hline 16 & Male & 68 & Married & $\mathrm{PhD}$ & Manager & 32 \\
\hline 17 & Male & 56 & Married & Doctor of medicine & Manager & 29 \\
\hline 18 & Male & 48 & Married & $\mathrm{PhD}$ & Manager & 21 \\
\hline 19 & Female & 44 & Married & M.S & Manager & 18 \\
\hline 20 & Female & 39 & Single & B.S & Health care provider & 15 \\
\hline 21 & Female & 32 & Single & B.S & Health care provider and manager & 8 \\
\hline
\end{tabular}




\section{A.3) Communication}

Communicating with patients and refugees is of high importance. From the point of view of PHC caregivers and providers, there are problems and obstacles for verbal communication in the initial contacts. Participants considered the refugees' language as an obstacle to this communication. In many cases, this lack of understanding and proper communication can lead to mistreatment.

"Refugees' language is an important issue. If they refer without any companion, it will be difficult to communicate with them, especially with the older people who do not know Persian, because we want them to understand what services we are providing and what kind of follow-up is needed." (Participant No. 3).

The PHC personnel with high work experience could understand refugees' language and communicate with them.

"I have not had difficulty in communicating with the refugees, and it was very easy for me to develop a relationship with them, but it did not happen in the first years of my job, rather after a few years, I could communicate with them easily. However, some of my colleagues could not really understand them." (Participant No. 6, with 29 years of work experience).

\section{A.4) Insurance}

Providing health care services will cost a lot for refugees and they cannot afford it. Also, from the perspective of the PHC providers, refugees do not believe in insurance coverage. The annual premiums are higher than the labor income of refugees.

"Many of the refugees complain about insurance. I have not communicated with them; they usually do not think about insurance in a useful way. For example, refugees have many family members, and only one of them may require some health care services, but a premium must be paid for all family members. Therefore, many of them do not get insurance at all because it is very costly." (Participant No. 5, manager).

\section{A.5) Previous health care records}

Previous records of the health care services and treatments provided in various fields such as maternal care, the treatment of diseases and vaccinations must be available both for refugees and nonrefugees. However, in many cases, such records do not exist or are incomplete for refugees.

"We see some refugees who have not received any treatments for 5-6 years or have not had any specific medical records. Sometimes, they request the previous record, although vaccination has not been done in our district. For example, they were vaccinated in another city or village and have lost the record. They are not good at keeping immunization records. "(Participant No. 8, with long experience of working with Afghans).

\section{A.6) Training}

Education and behavior change are a key component of the primary care recipient group. Despite the fact that primary health care is free, as refugees have a heavy workload, they only use such services in emergency situations.
"Whenever Afghans refer to the clinic, although I have been working here for many years and I am in charge of the clinic, I am so busy that I can only deal with maternal child care. They have many children, and we do not have much time, and the population under our coverage is growing increasingly. They are not just Afghans. We have to cover both, the Afghans and Iranian population." (Participant No. 20).

\section{A.7) Interorganizational information exchange}

Age, date of arrival, previous health status and treatment, family relationship, and number of children, and diseases within a family and household are important information that can help prevent diseases and even treat them more easily. The above-mentioned requires the refugees' exchange of accurate information with administrative and organizational agencies that provide health care services, especially in governmental agencies.

"It's very important for us to have information about the refugees, but whenever we requested statistics from departments, they do not have complete information about them or they say refugees' information is confidential." Without these statistics, we have to rely on their statements. In many situations, refugees try to give information that is in their interest and help them stay in the country. Therefore, they avoid providing information such as their illnesses and previous problems." (Participant No. 12, manager).

\section{A.8) Refugee identity}

The identification card is one of the important documents that identify refugees' identities. Refugees do not provide any card, visa, passport, or identity-based document when they visit health centers.

"It is difficult to identify refugees we have been dealing with so far, as most of them entered our province unofficially, but we try to gain their trust to obtain information, such as previous records, illnesses, and problems and the cause of migration, age, and family relationship, so that we can provide the right and the best health care service to them. They have neither national cards nor birth certificates." (Participant No. 18, manager).

\section{A.9) Number of children and family members}

The number of children and family members is an issue that challenges the size, type of work, and follow-up of refugees' health care. According to PHC managers and providers, refugees still tend to have more children. They do not believe in contraception and consider it a sin. Another issue regarding the number of children is that husbands demand the birth of more children, especially sons, which is one of the most important items for the male refugees.

"For example, you see the father-in-law of the woman who refers for health care services. The woman has 5 sons all of whom have to work and give their money to the grandfather. Therefore, the daughter-in-law does not play an important role in childbirth. I do not know whether they are Sunni or Shiite. However, most of Sunni Afghans do not believe in the two-year interval for breastfeeding. We tried to train them, but they refused it because the women played no role in this regard." (Participant No. 4). 
"Old Afghans were strongly interested in having many children believing that their body is healthy. They are biased about having sons. For example, one woman had 11 deliveries because she wanted 3 or 4 sons "(Participant No. 20).

On the other hand, some health care managers and providers believe that the new generation of refugees do not tend to have many children, and one of the reasons for this is the increase in living expenses and the reduction of income among the Iranians.

"A woman referring to the clinic has been living in Iran for 20 years. I asked her whether she wanted another child or not. She answered that she could not afford any other children. These are the words of new mothers, not their mother-in-law. Older people, especially the mother-inlaws, believe in having many children, and they do not consider other factors such as education or quality of life. Refugees living in Iranian cities have changed their minds and want to have few children and they are looking for comfort." (Participant No. 1).

\section{A.10) Vaccination}

Vaccination is one of the basic issues in the primary health care program. Refugees' refusal to receive the vaccine for their children and themselves, as well as the missing vaccination records of a large number of refugees are major challenges.

"I started vaccination for a refugee child from day one. (This baby had not received any vaccine to date). He again took a vaccine card, and I vaccinated him based on the intervals we have in our instruction. In the past, we relied on the memory of mothers, but nowadays everyone who has no record must go to the governor's office and take an empty vaccine card from the health center staff. Then, we will vaccinate them according to the schedule." (Participant No. 3).

On the other hand, one can refer to the delayed vaccination or non-vaccination. Also, refugees in Iran do not refer for vaccination for a variety of reasons, such as lack of information about its consequences. Also, the lack of specific vaccination card while referring to health centers is another challenge.

"When they refer to the clinic without a specific medical record, it is not known whether they had been vaccinated. Most of them have no card. For example, one person referred to the clinic who suffered from malaria, but it was not clear whether he had taken the medication. In short, their medical records are very confusing." (Participant No. $6)$.

\section{B. Challenges after receiving primary health care \\ B.1) Access to refugees after receiving primary health} care

Reaccess to refugees for subsequent follow-ups is hard and difficult due to various reasons such as an incorrect registered address.

"When we treat Afghans, sometimes they leave the clinic without completing the treatment, and we cannot reach them. For example, they receive some health care services which must be continued and require follow-up. However, we cannot locate them because there is no address." (Participant No. 2).

From the perspective of managers, the refugees give wrong addresses because they fear of being deported or returned to Afghanistan.

"When our colleagues ask the Afghans for addresses, they will respond with fear. They think that we want their addresses for other purposes, and we must explain to them that the address is required for future follow-up and health care. However, they do not trust us with an address, which makes future services and follow-up difficult." (Participant No. 15).

Access to refugees is also difficult due to the change of address that happens after receiving the health care service because of being a tenant. Failure to respond to telephone calls of health centers, changed telephone numbers, and unavailability of refugees' call numbers are other problems.

"One refers to the clinic with a name, and you have a fixed record of him. For example, a person was treated with a name and retreated with another name. For instance, for treating tuberculosis, the patient should be checked for drug resistance. Sometimes, they do not spell their name correctly, or they give wrong addresses because of lack of knowledge or not willing to be accessed." (Participant No. 4).

\section{B.2) Leaving and discontinuing treatment}

Medical follow-up in diseases that require long-term treatment such as tuberculosis is particularly important.

One of the primary health care providers working on tuberculosis treatment says:

"The experiences I have had with the refugees are related to their treatment; they usually continue the free treatment more easily. However, when their addresses change, or they are deported to Afghanistan, their treatment remains incomplete. They leave Iran without informing us, so we do not know whether they continue or stop their treatment." (Participant No. 2).

\section{B.3) Referral}

Sometimes, the refugees do not refer for health care follow-up. There is also no clear feedback of their referrals and the services to report and record actions taken at a health center or facility.

"After providing them with health care services, we must refer them in case of pregnancy and laboratory tests, but sometimes they do not come to the clinic and referral is not completed." (Participant No. 13).

"Referral and what we know about services and care are very important to us and care is interdependent, but this is not always the case and there are reasons for referral deficiencies. However, we cannot claim that referrals are made in the Iranian population as well."

\section{B.4) Lack of proper information structure}

The lack of complete and up-to-date information infrastructure (even before service delivery) is a challenge that managers and health care providers have greatly emphasized. Failure to record information by the source country 
due to migration and no legal and specific way for immigration are among the main challenges. Most refugees entered Iran illegally, and a small number of refugees have an accurate profile and identity.

"The exact information, the identity, and medical records of the refugees are fundamental and are the starting point for the record filing and other actions. This structure has not been available for many years, although its importance is being understood. Also, when the refugees receive the health care services, their record must be registered and kept. Following health reform plan and SIB system, this problem is about to be solved for refugees, and now we are registering health care information in the system of the Ministry of Health, but we cannot access legal specifications systemically, and this is one of the essential requirements. "(Participant No.16, a manager with long years of experience).

\section{Opportunities}

The results of this study showed that in addition to the challenges in the primary health care of refugees, there are many opportunities in the Islamic Republic of Iran to provide health care services for refugees, some of which are unique and justifiable in the world.

\section{C.1) Providing primary health care free of charge}

The government pays for all PHC services free of charge and offers the services to refugees with or without a residence card.

"We will provide all health care services free of charge in Iran, and refugees will be able to get these services like our own families and pay nothing. We provide all the care services for free in Iran and refugees can get these services just like our families and not pay a single penny. Perhaps the free services has led many to visit health centers more and to be more inclined to refer to health centers, clinics, and the like" (Participant No.14).

\section{C.2) Availability of health care services for refugees}

Free health care services are always available to refugees in Iran during working hours in comprehensive urban and rural health centers, health houses in villages, and health centers in cities.

One of the middle managers says:

"Like the Iranians, refugees can refer to all health centers during the working hours and receive services, especially in the area of prevention. Health care centers are dispersed in different parts of the city and even in villages; and there is no restriction for refugees' referral." (Participant No. 11).

\section{C.3) Justice and equality}

All primary health care services are done without exception and any preconditions for refugees.

"In general, we do not care whether they are Iranian or Afghan; they all sit and enter the room one by one. The services are the same. We do everything for both the Afghans and the Iranians." (Participant No. 4).

"We develop health care plans for refugees, and our department specifically performs refugee health care affairs, and they are announced to all universities. We receive care indicators from universities, compare, and control them. Also, the UNHCR supervises the plans because it pays money for some, watches and observes them, and we have to be accountable for it. "(Participant No. 16, manager).

\section{C.4) Insurance}

There are many different types of insurance coverages in Iran and refugees themselves or the High Commissioner for Refugees can apply for. One participant said, "There are various types of insurance companies in Iran and refugees can be assured individually or in group. Group insurance can have good discounts. The number of insured people has increased which is the subject of competition among insurance companies."

\section{Solutions}

The results of this study showed that each of the groups participating in this study, including health care providers and managers, had recommendations, strategies, and experiences that could help facilitate the provision of primary health care for refugees.

\section{D.1) Training}

Training is one of the best methods of solving the problems and challenges of refugees, especially in the health care area.

A manager working in health care system says:

"The Afghans who come to our center pay a lot of attention to training, and we are training them on a variety of subjects such as vaccines and exclusive breastfeeding. They are very good at observing and learning." (Participant No. 4).

On the other hand, there was a lack of opportunities for training while providing health care services.

"Refugees or Afghans are very perceptive when receiving training, especially the free-of-charge training and they listen well. However, we do not have enough time and opportunity to train them in one session and we should invite them again but they have young kids, and it is difficult for them. Therefore, we train them about vaccination and nutrition during maternal-child care." (Participant No. 20, health care provider).

According to participants, one of the main ways to train refugees is to use refugees themselves to provide training and services.

"We should use staff who are either Afghans or those who have worked with them more. We have been doing the same in the refugee camps for a long time. We brought some of Afghans to the department and trained them. We have been doing this for many years now in refugee camps. We train them for 6 months and then they would help out with the doctors and midwives in the clinics. Now, they are assisting the personnel, physicians, and midwives in the clinics inside the camp. I think it should be done in the cities as well. "(Participant No. 16, manager).

\section{D.2) Understanding the refugees' language}

To provide comprehensive coverage of primary health care services to refugees, services must be understandable 
and both the health care recipient and the provider can establish appropriate communication. Therefore, managers suggested that the Afghan professionals who are fluent in the refugees' language be used in the health centers.

"It is best if there would be a health care center exclusively for the Afghans, and the personnel should know how to communicate with them." (Participant No. 14, manager).

\section{D.3) Insurance}

The increase in treatment costs has doubled the importance of insurance coverage in recent years. Concerning the existence of various insurances in different conditions in the country, any insurance coverage can solve the payment problem and improve the health of the refugees. Insurance should be consistent and provide the services for refugees in an understandable and accessible form.

"It is better for refugees to have a comprehensive insurance policy. It does not matter whether international organizations pay the cost or the refugee. An isurance coverage that is acceptable in all health care centers should be available to them. The insurance coverage should be long term. For example, insurance is announced this year but it takes some months to reach the refugees and when they are covered by the insurance, its time is expired." (Participant No. 12).

\section{D.4) Identifying needs}

Identifying the needs and problems of refugees helps better plan for them, which can prevent waste of resources.

"In my opinion, before providing any services to refugees whether health care or other, we should evaluate what kind of problems they have had for which they had to migrate. We may plan for them but what we do may not be their priority, and they may have other problems which have been hidden from our eyes." (Participant No 19, manager).

\section{D.5) Comprehensive information system}

A comprehensive information system should include all information of refugees that is simultaneously available to all organizations. It is one of the main issues raised by managers.

"I believe that there should be an essential mechanism in Iran to record refugees' information and care. Now the Ministry of the Interior has a series of registration and information systems. We have a separate annual census in the camps, and we will have urban refugees' information only if they come to the health centers. Otherwise, there is nothing. I think that the Ministry of the Interior should take a specific process preferably electronically to register and identify these people, and all organizations and the ministries serving refugees should use the information." (Participant No. 14, executive manager).

\section{D.6) Formulation of instructions for Health care provi-} sion

The provision of health care services at all levels requires instruction and service delivery process, and currently, health care services for refugees are provided according to caring components for Iranians while the managers demanded the development of separate instructions based on the needs of refugees throughout the country.

"In my opinion, after all these years, with this number of refugees in the country, clear instructions should be codified by the Ministry of Health and the help of universities. Then, they should be implemented equally after the pilot stage in the country. Nowadays, universities and provinces provide refugees with care services. In my opinion, equalization and equity should be done in this regard." (Participant No. 16).

\section{Discussion}

The present study was conducted qualitatively with the participation of health care providers. This study found that the health care providers face many challenges during and after the provision of primary health care to refugees that led to their dissatisfaction and poor quality of service. Refugees often have complex and different health care needs, and PHC services must address these challenges both during and after health care provision and provide care at the right time (16). One of the key reasons in the lack of provision of PHC to refugees is the shortage of professional and trained personnel and the significant lack of refugees' training by health care personnel (17). Joon et al (2014) studied the training and illegal immigration status of refugees for primary health care services and showed that human resource shortages in the health care sector are widely recognized as a key barrier (18). Also, lack of sufficient training opportunities, poor service organization, and a lack of understanding of health care providers' language discourage the refugees to receive training $(16,17)$. Limitations on regional language skills have an impact on the quality and accessibility of treatment, and communication with patients and refugees is a major requirement to achieve accurate treatment and gain their trust (16). Limited access of refugees to health care can be due to communication problems and lack of knowledge about health care systems (19). The importance of establishing a proper relationship with refugees has been proven in recent studies, such that studies of Spike et al (2010), Pottie et al (2014), and Susan et al (2014) introduced language translation and communication support as facilitators of health care services $(7,20,21)$.

Many refugees do not have access to primary health services (22). The results of the study of Spike et al (2010) on refugees' access to PHC revealed that access to health care services was provided only by a health card, and there was no official policy for refugees to access the services in the northern part of Australia (7). Access to health care services and the patient's interaction with the care system affect treatment adherence of patients (19). Health care costs, lack of insurance, poor training, poor referral system, poor access to refugees, poor need assessment, lack of health and identity card are reasons for refugees and patients not to adhere to their treatment regimen $(7.16,17,19,20,23,24)$. Because of the fear of returning to Afghanistan and previous bitter experiences in their country, refugees do not provide full details and information, in particular, religion, and they do not have identification cards and are reluctant to receive protection from the destination country $(1-4,6,16)$. 
Specifications such as age, care status, and previous problems and illnesses, previous records of vaccinations, and medications taken in the past are essential to file records and provide any care. Unfortunately, such information is incomplete for refugees and in most cases, there is no information (16). According to Phillips et al (2007), the majority of Afghan refugees were unaware of their vaccination records and thus they proposed a system involving age, vaccination history, and report on the modified cases that supported public health units and improved the quality of services (25). Primary health care services rarely match the needs of immigrants, which makes this group more vulnerable. Therefore, the correct need assessment and identification of the refugees' problems can help resolve them thoroughly and prevent the waste of resources (20). In the studies of Joshi et al (2013) and Pottie et al (2014), the use of bilingual translators, low cost and free services, free travel to health centers for better access to refugees, the creation of appropriate information structure, and comprehensive health care and training of the health care providers were considered as strategies to improve the quality of health care services provided to refugees $(16,20)$. Hascio et al (2009) also recommended establishing a strong information system for refugees that can address the public health challenges created by refugees (26).

\section{Conclusion}

The results of this study led to identifying the challenges, opportunities, and solutions to the process of providing primary health care to refugees. It is suggested that the quantity and quality of management in this area be improved, especially in the refugee population, which can be done by addressing the challenges in providing health care, building infrastructure for better use of solutions and opportunities, and identifying needs and resolving barriers and requirements. Given the lack or incompleteness of the existing database on refugee health records, it is suggested that a refugee database be prepared in Iran and health care be registered and information be shared among related organizations. Managers and experts who play a pivotal role in the health care system should enhance their scientific, managerial, and executive knowledge to strengthen their academic management capability. It is also suggested that a training program be developed to increase the knowledge of refugees about health care, to change the health culture of refugees, and to increase health indicators. Finally, further studies should be conducted to examine the challenges and opportunities of Afghan refugees in Iran with respect to health care services and challenges.

\section{Acknowledgments}

This manuscript has been derived from a $\mathrm{PhD}$ thesis, supported financially by Iran University of Medical Sciences (Grant No. IUMS/SHMIS-1394/37). We thank all the Afghan refugees who participated in this study. Also, our thanks go to all managers and experts who helped us in the implementation of this comprehensive research.

\section{Conflict of Interests}

The authors declare that they have no competing interests.

\section{References}

1. Alibabaei Y, Jamshidiha G. Factors affecting the return of Afghan refugees on the basis of famous residents of Mashhad Golshahr. Sociological Rev. 2002;20:71-91.

2. Otoukesh S, Mojtahedzadeh M, Cooper CJ, Tolouian R, Said S, Ortega $\mathrm{L}$, et al. Lessons from the profile of kidney diseases among Afghan refugees. Med Sci Monit. 2014;20:1621-7.

3. Yazdanpanahi M, Masjedi H, Hoseini M, Velayati A, Masjedi M. TB disease in Afghan and Iranian patients referred to the National Research Institute of Tuberculosis and lung diseases 1379-1377. Hakim R. 2002;5(4):241-8.

4. Joshi C, Russell G, Cheng IH, Kay M, Pottie K, Alston M, et al. A narrative synthesis of the impact of primary health care delivery models for refugees in resettlement countries on access, quality and coordination. International journal for equity in heal. Int $J$ Equity Health. 2013;12(1):88.

5. Bartkovjak M, Krcmery V. Spectrum of infectious diseases among internally displaced refugees in South Sudan and north Kenya. Int J Infect Dis. 2014;21:26-7.

6. Eckstein B. Primary care for refugees. Am Fam Physician. 2011;83(4):429-36.

7. Spike EA, Smith MM, Harris MF. Access to primary health care services by community-based asylum seekers. Med J Aust. 2011;195(4):188-91.

8. Harris MF. Access to preventive care by immigrant populations. BMC Med. 2012;10:55

9. hoseini M, Ranjbar R, Sarshar M, Ebrahimi E. The frequency of positive HBsAg Afghan of street cleaners working in Tehran in 2009. Iranian J I Dis . 2013(61):49-53.

10. Fletcher M. Five domains of information technology governance for consideration by boards of directors: University of Oregon; 2006.

11. Iranmanesh S, Banazadeh M, Forozy MA. The Relationship Between Nurses' Perception Of Barriers Magnitude And Their Demographic Characteristics. i-Manager's Journal on Nursing. 2015;5(1):11-22.

12. Nouri Hekmat S. Implementation of services quality (SERVQUAL) tool in Hazrate Rasoule Akram hospital [dissertation]. Tehran: Tehran Univ Med Sci. 2006: 60-62. (Persian).

13. Streubert HJ, Rinaldi Carpenter D. Qualitative reseasrch in nursing advancing the humanistic imperative. 5th, editor. USA: Lippincott Williams \& Wilkins; 2011

14. Lobindo-wood G, Haber J. Nursing reaserch methods and critical appraisal for evidance based practice. 7th, editor. USA: Elsevier; 2010. 15. Gale N, K, Heath G, Cameron E, Rashid S, Redwood S. Using the framework method for the analysis of qualitative data in multidisciplinary health research. BMC Med Res Methodol. 2013;13(1):117.

16. Joshi C, Russell G, Cheng I, Kay M, Pottie K, Alston M, et al. A narrative synthesis of the impact of primary health care delivery models for refugees in resettlement countries on access, quality and coordination. Int J Equity Heal. 2013;12:88.

17. Wanzira H, Muyinda R, Lochoro P, Putoto G, Segafredo G, Wamani $\mathrm{H}$, Lazzerini M. Quality of care for children with acute malnutrition at health center level in Uganda: a cross sectional study in West Nile region during the refugee crisis. BMC Heal Serv Res. 2018;18:561.

18. Ehiri JE, Gunn JK, Center KE, Li Y, Rouhani M, Ezeanolue EE. Training and deployment of lay refugee/internally displaced persons to provide basic health services in camps: a systematic review. Glob Health Action. 2014;7:23902.

19. Wångdahl J, Lytsy P, Mårtensson L, Westerling R. Health literacy among refugees in Sweden - a cross-sectional study. BMC Public Health. 2014;14(1030):1-12.

20. Pottie K, Batista R, Mayhew M, Mota L, Grant K. Improving delivery of primary care for vulnerable migrants: Delphi consensus to prioritize innovative practice strategies. Can Fam Physician. 2014;60(1):e32-40.

21. Lee SK, Sulaiman-Hill CR, Thompson SC. Overcoming language barriers in community-based research with refugee and migrant populations: options for using bilingual workers. BMC Int Health Hum Rights. 2014;14:11.

22. Rakhshani F, Ansarimoghadam A, Hor A. Knowledge, attitudes and behaviors of Afghan refugee women residing in Zahedan about family planning. J Reprod Infertil. 2002;3(4):47-54.

23. Haskew C, Spiegel P, Tomczyk B, Cornier N, Hering H. A standardized health information system for refugee settings: rationale, challenges and the way forward. Bull World Heal Organ 2010;88:7924. 
24. Dehghan nayeri N, Mohammadi S, Pedram razi S, Arazi T, Kazemnejad A. Effectiveness of family empowerment program on level of adherence to treatment regimens in stroke patients; a randomized controlled trial. Evidence B Care. 2015;5(1):57-66.

25. Phillips CB, Benson J. Better primary health care for refugees Catch up immunisation. Aust Fam Physician. 2007;36(6):440-3.

26. Haskew C, Spiegel P, Tomczyk B, Cornier N, Hering H. A standardized health information system for refugee settings: rationale, challenges and the way forward. Bull World Health Organ. 2010;88(10):792-4. 